notice, however, he or she may fail to report them for the same reasons that accidents go unreported-namely, apathy, fear of litigation, and ignorance of the reporting arrangements. In this, farmers differ little from employers in other industries, and much better systems of surveillance are badly needed throughout British workplaces. ${ }^{9}$ Less awareness and a more fatalistic acceptance of hazards at work are, however, found in farming.

The Health and Safety Executive has been developing special initiatives to counter this, such as producing targeted educational materials and individual health cards, and certain legislative measures, such as the Control of Substances Hazardous to Health (COSHH) Regulations and the recently introduced maximum exposure limited for grain dust, ${ }^{10}$ are expected substantially to increase awareness. Research currently sponsored by the Health and Safety Executive includes projects on grain dust, zoonoses, and sheep dipping (J Wattie, personal communication).

But with the present limited availability of occupational health services in the United Kingdom how can health professionals do more to improve the lot of farmworkers? General practitioners in rural areas continue to be the main point of contact for farmers and their families, yet their training to recognise occupational health problems, including the short term and possible long term effects of exposure to pesticides and other chemicals, is limited. This could be partly rectified by encouraging them to attend the introductory courses in occupational medicine that take place under the auspices of the Faculty of Occupational Medicine. (These could be slanted more to the needs of farmworkers and similar high risk occupational groups such a construction workers. ${ }^{11}$ )

The growing number of NHS hospital consultants in occupational medicine and their increasingly outward looking occupational health services could also provide expert advice on individual patients. In addition, rural practices could undertake health promotion activities targeted at the special needs of farming families.

For occupational health professionals agriculture shows the need to incorporate assessments of environmental impact into their training and practice. This is not only another example of "good earthery" but would represent an important shift in direction for the specialty. Agricultural policies - particularly those that intensify and increase productivity ${ }^{12}-$ may affect occupational and environmental health and safety, and these policies cry out for risk assessment. Two examples are the use of pesticides ${ }^{3}$ and the method of keeping livestock in confined areas, which poses new respiratory hazards to workers ${ }^{2}$ exposed to contaminants of the animal house air and possibly also to the public from these bio-aerosol emissions.

Agribusiness is becoming increasingly capital intensive, with further reductions in the workforce expected from farming reforms initiated by the European Community. These include the requirement that land be set aside out of production, which could disrupt the balance and speed of work and lead to other, less foreseeable consequences. ${ }^{513} \mathrm{How}$ may this legislation affect the risks of accident to workers and to the public enticed to pursue leisure activities on set aside land?

Occupational health doctors will need to work more closely with their colleagues in public health medicine to achieve these innovatory advances in prevention. If doctors want to exert greater influence over industry and the government on matters of occupational and environmental health then agriculture is a good place to start. ${ }^{14}$

PETER J BAXTER

Consultant Occupational Physician,

Department of Community Medicine,

University of Cambridge Clinical School,

Addenbrooke's Hospital,

Cambridge CB2 2QQ

1 Johns M. European year of health and safety. Toxic Substances Bulletin 1992;18:1-2

2 May JJ. Issues in agricultural health and safety. Am $\mathcal{F}$ Ind Med 1990;18:121-31.

3 The BMA guide to pesticides, chemicals and health. London: Edward Arnold, 1992.

Centers for Disease Control. Surgeon general's conference on agricultural safety and health, 1991. MMWR 1992;41:5-12.

Croft P, Coggon D, Cruddas $M$, Cooper C. Osteoarthritis of the hip: an occupational disease in farmers. BMF 1992;304:1269-72.

6 Cameron D, Bishop C. Farm accidents in adults. BMJ 1992;305:25-6.

7 Cameron D, Bishop C, Sibert JR. Farm accidents in children. BMF 1992;305:23-5.

Watkins SA. Leptospirosis as an occupational disease. Brf Ind Med 1986;43:721-5.

Carter JT. There's a lot of it about? $\mathrm{Br} f$ Ind Med 1991;48:289-91.

10 Health and Safety Executive. Occupational exposure limits 1992. London: HMSO, 1992 (EH490/92).

11 Snashell D. Safety and health in the construction industry. BMF 1990;301:563-4

12 Donham KJ. Prologue: agricultural occupational and environmental health: policy strategies for the future. Am F Ind Med 1990;18:107-19.

13 Richardson D. A harvest of sorrows. Financial Times May 23/24:7.

14 Delamothe T. Airs, waters, places, and doctors. BMF 1992;304:268.

\title{
Trauma, back pain, malingering, and compensation
}

\section{No dependable spine "lie detectors" yet}

The dawn of the railway age was associated with frequent railway accidents, and many passengers suffered injuries to their spines and developed chronic back pain. "Railway spine" was often the subject of litigation. Debate raged about whether this was "concussion of the spine", 1 minor organic brain damage, ${ }^{2}$ hysteria, or deliberate malingering associated with the prospects of compensation. ${ }^{3}$ Similar arguments are made today in medicolegal claims for back pain.

Commonly a patient has had an accident, most often at work or in a car, and has developed back pain, perhaps referred into the lower limb. Most acute episodes of back pain resolve over a few days or weeks, but some people despite extensive treatment (which may include surgery) develop persistent and widespread symptoms and become severely disabled. The problems seem grossly disproportionate to objective evidence of damage in the spine, even that obtained with the most sophisticated investigations, including mag- netic resonance imaging and computed tomography. A legal claim is made, which drags on for several years. Although agreement is reached about who was at fault in the accident, the argument continues about the severity of the injury and whether the patient is really suffering pain and is disabled.

Henry Miller introduced the term "accident neurosis" to describe a series of patients with psychoneurotic complaints after trauma. ${ }^{4} \mathrm{He}$ suggested that the process of seeking compensation plays an important part in the chronicity of the symptoms. A comparison of two groups of patients with similar degrees of back injury - one group seeking compensation and the other for whom no compensation was availablesupports this. It found that the severity of pain, disability, and psychological disturbance and the duration of unemployment and time off work were significantly greater in the group seeking compensation. ${ }^{5}$

The compensation process itself, with its prolonged series 
of visits to lawyers and doctors for medical reports, is a disincentive to recovery. Rapid improvement after the accident would mean a smaller financial settlement. Other compensations may also play their part - such as the care and attention received from relatives, friends, therapists, and doctors, which act as psychological reinforcers of chronic pain and disability. Depression and anxiety are common and may amplify the severity of the symptoms. Depression and anxiety may be either the cause or the result of chronic pain and disability; most likely a vicious circle exists, with physical symptoms and depression amplifying each other.

Although Miller suggested that most patients recover rapidly within a few months of settlement of their claims, ${ }^{4}$ more recent studies suggest that this is not so. ${ }^{56} \mathrm{~A}$ major difficulty therefore lies in determining how much of the symptoms is directly due to tissue damage in the spine; how much is subconscious amplification of a minor problem, which is nevertheless perceived as severe pain and results in chronic disability; and how much is fabrication.

Clearly, if someone is injured in an accident he or she should be compensated for the pain and suffering experienced and any resultant loss of income. Compensation should be given for pain and suffering primarily of psychological origin but resulting from the injury, as well as physical damage, but they must be distinguished from deliberate malingering. What should happen if the process of seeking compensation itself is responsible for the subconscious amplification and prolongation of symptoms? Is it right that this in turn should merit further compensation?

A series of signs on simple physical examination helps to identify patients with a substantial non-organic component to their problem. ${ }^{7}$ These include overreaction with obvious "pain behaviour" such as facial expressions, shaking, and falling to the ground; widespread superficial tenderness in a distribution not corresponding to any anatomical distribution; the reproduction of symptoms by simulated stress on the spine by rotation of the shoulders and pelvis together or axial loading by pressure on the skull; the finding on formal testing of severely limited straight leg raising in a patient who can sit forwards with the legs extended; and regional disturbances with severe lower limb weakness or sensory loss not corresponding to any nerve root distribution. A single positive test result is not enough to label a patient as having a substantial non-organic component to the problem, but when several results are positive this is very likely.

The difficulty lies in distinguishing those who deliberately exaggerate their symptoms from those with a genuine cause for their pain. The spine "lie detector" has recently attracted publicity as an instrument for making this distinction. ${ }^{8}$ The patient is strapped into a metal frame that allows flexibility of spinal movements. Isokinetic measurements are made in which the speed of any movement is preset and the maximum force that the patient can achieve during that movement is determined. Alternatively, in isoinertial movements the patient works against a preset resistance and the velocity varies according to the effort applied by the patient. Measurement shows a high degree of reproducibility with reduced function in patients with low back pain, ${ }^{9}$ and poor performance correlates with excessive illness behaviour. ${ }^{10}$ The apparatus is useful in physical rehabilitation by providing an index of how the back is working and indicating goals for improvements in trunk performance. ${ }^{11}$
The particular medicolegal interest is in using these dynamometric techniques to distinguish the malingerer, the hypothesis being that the malingerer does not try properly. Accurately reproducing submaximal effort is virtually impossible: malingerers would therefore be identified by the lack of consistent measurements made on repeated testing. The patient is asked to perform repeated maximal isokinetic or isoinertial movements and the amount of variance between repetitions computed. Exceeding the norms indicates "lack of effort" and implies that it is likely to be deliberate.

Although studies in healthy volunteers found greater variance in subjects deliberately producing submaximal efforts, it is noteworthy that the authors had difficulties in analysing the data and emphasised the need for clinical judgment in interpreting performance. They found no specific patterns of measurements to correlate with submaximal effort. ${ }^{12}$

The approach therefore remains controversial. The hypothesis that variance above a certain level in patients with back pain means submaximal effort has not been validated and there is no standard for malingering to check this against. In particular, could the apparatus distinguish the patient with a very substantial subconscious psychological contribution towards pain and disability from the deliberate malingerer? Both seem likely to produce submaximal efforts on dynamometric testing.

In many of these patients the direct effects of the physical injury, the psychological reactions, and the quest for compensation become inextricably intertwined. Careful observation and examination are important, particularly to identify those who deliberately exaggerate their problems. Dynamometric measurements cannot be taken as the final arbiter.

Professor of Rheumatology,

MALCOLM IV JAYSON

Rheumatic Diseases Centre,

University of Manchester,

Hope Hospital,

Salford M6 8HD

1 Erichsen JE. On concussion of the spine. London: Longmans, Green, 1875

2 Walton GL. Possible cerebral origin of the symptoms usually classified under "railway spine." Boston Medical and Surgical foumal 1883;109:337-40.

3 Prince M. Association neuroses: a study of the pathology of hysterical joint affections, neurastheni and allied forms of neuro-mimesis. I Nerv Ment Dis 1891;18:257-82.

Miller H. Accident neuroses. BMF 1961;i:919-25,992-8.

5 Miller H. Accident neuroses. BMJ 1961;i:919-25,992-8. 1989;14:947-55.

6 Guest GH, Drummond PD. Effect of compensation on emotional state and disability in chronic back pain. Pain 1992;48:125-30.

Waddell G, McCulloch HA, Kummel E, Venner RM. Non-organic physical signs in low-back pain. Spine 1980;5:117-25.

8 Seton C. Lie detector women awarded $£ 220,000$ for back injuries. Times $1992 \mathrm{Jan} 29: 3$

Szpalski M, Federspiel CF, Poty S, Hayez JP, Debaize JP. Reproducibility of trunk isoinertial $\sigma$ dynamic performance in patients with low-back pain. Journal of Spinal Disorders 1992;4:78-85.

10 Hirsch G, Beach G, Cooke C, Menard M, Locke S. Relationship between performance on lumbar dynamometry and Waddell score in a population with low-back pain. Spine 1991;16:1039-43.

11 Hazard RG, Fenwick JW, Kalisch SM, Redmond J, Reeves V, Reid S, et al. Functional restoration programme with behavioural support. Spine 1989;14:157-61.

12 Hazard RG, Reid S, Fenwick J, Reeves V. Isokinetic trunk and lifting strength measurements: variability as an indicator of effort. Spine 1988;13:54-7.

\section{Correction}

Thinking through a salaried service for general practice

Owing to an editorial error reference 13 was omitted from the list of references in 0 this editorial by Steve Iliffe (6 June, pp 1456-7).

13 Stanworth J, Smith B. Franchising for the small business. Oxford: Blackwell, 1991 .

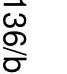

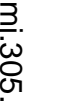 8 \\ ר.}

